\title{
Preventing hip fractures with multidisciplinary teams: a Canadian perspective
}

\author{
Ethan Sanders, BSc \\ Johanna Dobransky, MHK \\ Lara Cheaitani, BSc \\ Nicole Harris, BSc \\ Allan Liew, MD \\ Steven Papp, MSc, MD \\ George Grammatopoulos, \\ MBBS, DPhil
}

Accepted June 8, 2020

\author{
Correspondence to: \\ G. Grammatopoulos \\ Room W1638, Box 502, \\ Division of Orthopaedic Surgery \\ University of Ottawa \\ The Ottawa Hospital \\ 501 Smyth Rd \\ Ottawa ON K1H $8 \mathrm{~L} 6$ \\ ggrammatopoulos@toh.ca
}

DOI: $10.1503 /$ cjs.014219
Fragility fractures (FFs) are low-energy trauma fractures that occur at or below standing height. Among FFs, hip fractures are associated with the greatest morbidity, mortality and cost to Canadian health care systems. This review highlights the current state of medical care for hip fractures in Canada, with specific focus on the role of the multidisciplinary team. Gaps in care exist, as FFs represent a unique challenge requiring both acute and chronic management. Furthermore, there is a lack of ownership of FFs by a medical specialty. These gaps can be addressed through the use of multidisciplinary teams, which have been shown to be efficacious and cost-effective. This model of care also addresses numerous patient-identified barriers to treatment, including inadequate patient counselling. However, there is still room for improvement in both the identification of patients at risk for hip fracture and patient adherence to therapy.

Les fractures de fragilisation (FF) sont des fractures qui surviennent lors d'un traumatisme léger se produisant depuis la position debout ou d'une hauteur moindre. Les fractures de la hanche sont les FF associées aux plus grands taux de morbidité et de mortalité et aux plus grands coûts pour les systèmes de santé au Canada. La présente revue s'intéresse à l'état actuel des soins médicaux pour une fracture de la hanche au pays et porte une attention spéciale au rôle de l'équipe multidisciplinaire. Des lacunes dans les soins existent et sont mises en évidence par les FF, qui posent un défi bien particulier en nécessitant une prise en charge à la fois aiguë et chronique. De plus, cette prise en charge ne relève d'aucune spécialité médicale. La correction de ces lacunes peut passer par le recours aux équipes multidisciplinaires, dont l'efficacité et la rentabilité ont été démontrées. Ce modèle de soins élimine également de nombreux obstacles au traitement signalés par les patients, y compris le counseling inadéquat. Des améliorations sont néanmoins encore nécessaires dans l'identification des patients à risque de fracture de la hanche et dans l'observance du traitement.

$\mathbf{F}$ ragility fractures (FFs) are low-energy trauma fractures that occur at or below standing height. ${ }^{1}$ They are often considered a disease of old age, with $25 \%$ of females and $12 \%$ of males older than 50 years affected. ${ }^{2}$ Fragility fractures cost Canadian health care systems nearly $\$ 2$ billion annually, and the cost is expected to triple over the next 20 years owing to the aging population. ${ }^{3}$ The most common sites for FFs are the vertebrae, distal radius and neck of femur (i.e., hip fracture).$^{4}$ Of these, hip fractures are associated with the greatest morbidity, mortality and cost. In Canada, 30000 people break their hip annually. ${ }^{5}$ In patients older than 50 years, the 1 -year mortality rate associated with a hip fracture is $24 \%$; even if these patients survive, half will have some degree of long-term disability, and $25 \%$ will require long-term care in a nursing home. ${ }^{4}$

More than half of hip fractures are preceded by a prior fracture. Despite the availability of effective treatment (antiresorptive therapy, which reduces the risk of secondary fracture by $40 \%-60 \%{ }^{6}$ ) and the $86 \%$ increased risk of any fracture after just 1 fracture, the Canadian Multicentre Osteoporosis Study investigators found that less than $56 \%$ of women received secondary prevention after an FF. ${ }^{6,7}$ To highlight the magnitude of the lack of secondary prevention, consider the example of a heart attack. After the acute management of a myocardial infarction, numerous preventive measures such as medications and lifestyle counselling are implemented to reduce risk factors. To 
not receive comprehensive follow-up after a heart attack would be inappropriate. Although the implications of a heart attack are apparent more immediately, an FF is of similar consequence in the subacute period.

A fundamental shift needs to occur in which an initial nonhip FF is considered a "bone attack" and leads to appropriate follow-up care and intervention beyond the acute stage. ${ }^{4}$ This can lead to prevention of costly hip fractures. In particular, the multidisciplinary team has been shown to be a cost-effective method of reducing the incidence of these fractures..$^{1,2,8-13}$

In this review, we highlight the current state of care for femoral neck fractures in Canada, with specific focus on the role of multidisciplinary teams to manage patients at risk, and future directions as guided by patient perspectives on quality of care. We reviewed retrospective studies, randomized controlled trials, meta-analyses and qualitative studies (Box 1 and Table 1).

\section{GAPS IN MANAGEMENT}

There are currently many multifaceted gaps in the care of patients with hip fracture in Canada. The disconnect in the transition from acute to chronic care exists as a result of a distinct divide, which is notably shown by FFs. The identifying event is often a hip FF, for which the patient presents to the emergency department and receives care by an emergency physician and an orthopedic surgeon. The chronic management of osteoporosis (the underlying cause of the FF), however, is managed by rheumatologists, geriatricians, physiatrists, endocrinologists and family physicians. ${ }^{16}$ This divide is met with a lack of compensation for the coordination of care among these acute and chronic providers.

The current gap in care is perpetuated by the high turnover of trainees, for example, residents and fellows. ${ }^{4}$ Even when the diagnosis of osteoporosis is given to the primary care provider, along with information on appropriate steps, problems can arise. Osteoporosis is often seen as a low priority by primary care providers: rather than seeing osteoporosis as a treatable condition, many physicians still see it as an unpreventable part of aging. ${ }^{17}$ This directly contradicts evidence supporting the use of pharmacotherapy in the treatment of osteoporosis. ${ }^{1,6}$ The fact that many vertebral fractures are often overlooked is very clinically

Box 1: Search strategy and results

We performed a literature search of PubMed and MEDLINE that captured articles published between January 2004 and April 2020. We used the Medical Subject Heading "hip fracture" and including the following terms to refine the search: "fragility fracture" OR "osteoporotic fracture" AND "fracture liaison service" OR "multi-disciplinary team" OR "orthogeriatric" AND "Canada" OR "Canadian." The search generated 20 results, which were reviewed by 2 authors (E.S., J.D.). From this pool, we identified 10 key studies from 9 trials showing best-evidence results from Canadian centres on the outcomes of secondary fracture prevention programs. ${ }^{1,2,8-15}$ relevant, as this would be an essential time to initiate treatment of osteoporosis. Despite the challenges of diagnosis of vertebral fractures on history-taking and radiography, recognition of such fractures could provide an opportunity to prevent hip fractures, as a vertebral fracture entails a $300 \%$ increase in risk of a subsequent hip fracture. ${ }^{7}$ A similar relation exists with distal radius fractures. ${ }^{17}$ The majority of these gaps can be addressed through the use of multidisciplinary teams.

\section{IMPACT OF MULTIDISCIPLINARY TEAMS IN CANADA}

The multidisciplinary team is an example of a type A model of care. In FF care, type A models seek to identify, investigate and initiate treatment of patients, whereas type B models identify and investigate but do not initiate treatment. ${ }^{18}$ Multidisciplinary teams comprise physicians (primary care and treating physician) and nurses, typically functioning as case managers. ${ }^{13}$ The role of case manager may also be fulfilled by other allied health care professionals (e.g., physiotherapists, occupational therapists). The multidisciplinary team closely parallels the fracture liaison service (FLS), pioneered in the United Kingdom and Australia. Fracture liaison services rely heavily on the nurse manager, who takes on the role of service coordinator. This starts with identification of patients through emergency department records, fracture clinics, and inpatient and outpatient records. The next step involves assessment for osteoporosis; this step is not necessary in the evaluation of patients older than 50 years with an $\mathrm{FF}$, as a diagnosis can be inferred. In patients with an initial nonhip fracture, dual-energy radiographic absorptiometry should be performed to assess the bone mineral density. ${ }^{4}$ This examination is fairly cost-effective, with a mean cost of $\$ 83$ in 2016 in Ontario. ${ }^{19}$ The information from this test guides treatment decisions, of which the main modalities are exercise, nutritional counselling, physiotherapy, falls prevention and pharmacotherapy. ${ }^{4}$ Effective medical treatment includes bisphosphonates, selective estrogen receptor modulators, hormone replacement therapy, teriparatide and monoclonal antibodies (denosumab and romosozumab). ${ }^{1,20}$ The multidisciplinary team seeks to take a hospital-driven approach to addressing the gap in care in osteoporosis.

This hospital-based model has been recommended as the most effective model by Osteoporosis Canada. ${ }^{21,22} \mathrm{Sev}$ eral landmark studies have shown the relation between reduced cost and fracture liaison services. At the University of Alberta, Majumdar and colleagues ${ }^{2}$ conducted a randomized controlled trial (C-STOP Trial) to compare an active low-intensity control intervention (telephone call to the patient, explaining the link between osteoporosis and fracture, encouragement to follow up with primary care and a fax to the primary care physician with relevant resources) to a nurse-led case manager intervention in 
Table 1. Key Canadian studies on fragility fracture management with multidisciplinary teams

\begin{tabular}{|c|c|c|c|c|c|}
\hline Study & Design & $\begin{array}{l}\text { Duration of } \\
\text { follow-up }\end{array}$ & Patients & Outcome measure(s) & Findings \\
\hline $\begin{array}{l}\text { Majumdar et al., }{ }^{10} \\
2007\end{array}$ & $\begin{array}{l}\text { Randomized } \\
\text { controlled trial }\end{array}$ & $6 \mathrm{mo}$ & $\begin{array}{l}220 \text { patients aged } \\
\geq 50 \text { yr with hip FFs }\end{array}$ & $\begin{array}{l}\text { Bisphosphonate therapy, } \\
\text { bone mineral density testing } \\
\text { and initiation of appropriate } \\
\text { care with case manager } \\
\text { intervention compared to } \\
\text { usual care }\end{array}$ & $\begin{array}{l}\text { - Received bisphosphonates: } 51 \% \text { in case } \\
\text { manager group v. } 22 \% \text { in control group } \\
(p<0.001) \text {. } \\
\text { - Had bone mineral density testing: } 80 \% \text { in } \\
\text { case manager group v. } 29 \% \text { in control } \\
(p<0.001) \\
\text { - Received appropriate care: } 67 \% \text { in case } \\
\text { manager group v. } 26 \% \text { in control group } \\
(p<0.001)\end{array}$ \\
\hline $\begin{array}{l}\text { Sander et al., }{ }^{14} \\
2008\end{array}$ & $\begin{array}{l}\text { Decision analysis } \\
\text { model }\end{array}$ & $12 \mathrm{mo}$ & $\begin{array}{l}430 \text { patients at } \\
\text { St. Michael's Hospital } \\
\text { (major urban trauma } \\
\text { centre) as part of OECP }\end{array}$ & $\begin{array}{l}\text { Cost-effectiveness of } \\
\text { coordinator-led program, } \\
\text { changes in incidence of hip } \\
\text { fracture }\end{array}$ & $\begin{array}{l}\text { - Osteoporosis coordinator could reduce } \\
\text { number of hip fractures from } 34 \text { to } 31 \text {, } \\
\text { leading to cost savings of } \$ 48950 \\
\text { - This model could serve centres that see as } \\
\text { few as } 350 \text { FFs annually }\end{array}$ \\
\hline Sale et al., ${ }^{11} 2010$ & $\begin{array}{l}\text { Prospective cohort } \\
\text { study }\end{array}$ & $6 \mathrm{mo}$ & $\begin{array}{l}332 \text { patients at } \\
\text { Peterborough Regional } \\
\text { Health Centre }\end{array}$ & $\begin{array}{l}\text { Rates of postfracture } \\
\text { investigation and care with } \\
\text { coordinator-led program }\end{array}$ & $\begin{array}{l}\text { - } 51 \% \text { of patients had bone mineral density } \\
\text { testing done } \\
\text { - } 26 \% \text { of untreated patients had initiated } \\
\text { first-line treatment } \\
\text { - Coordinator was highly associated with } \\
\text { treatment initiation }\end{array}$ \\
\hline $\begin{array}{l}\text { Jaglal et al., }{ }^{9} \\
2012\end{array}$ & $\begin{array}{l}\text { Cluster randomized } \\
\text { controlled trial }\end{array}$ & $6 \mathrm{mo}$ & $\begin{array}{l}267 \text { patients from } \\
36 \text { community hospitals } \\
\text { (60-340 patients) }\end{array}$ & $\begin{array}{l}\text { Appropriate management } \\
\text { with centralized coordinator } \\
\text { compared to standard care }\end{array}$ & $\begin{array}{l}\text { - } 45 \% \text { of intervention group received } \\
\text { appropriate management, compared to } 26 \% \\
\text { of control group (absolute difference 19\%, } \\
\text { adjusted OR } 2.3 \text { [95\% Cl 1.3-4.1]) }\end{array}$ \\
\hline Roux et al., 2013 & $\begin{array}{l}\text { Randomized } \\
\text { controlled trial }\end{array}$ & $12 \mathrm{mo}$ & $\begin{array}{l}725 \text { patients aged } \\
>50 \text { yr with incident } \\
\text { FFs }\end{array}$ & $\begin{array}{l}\text { Treatment rates with } \\
\text { standard care, minimal } \\
\text { intervention or intensive } \\
\text { intervention; interventions } \\
\text { were intended to educate } \\
\text { and motivate patients and } \\
\text { primary care physicians, but } \\
\text { differed in frequency of } \\
\text { contact and information } \\
\text { content }\end{array}$ & $\begin{array}{l}\text { - Treatment rates increased significantly after } \\
\text { both interventions } \\
\text { - Only intensive intervention significantly } \\
\text { increased treatment rates in patients with } \\
\text { previous fractures }\end{array}$ \\
\hline $\begin{array}{l}\text { Bogoch et al., } \\
2017\end{array}$ & $\begin{array}{l}\text { Prospective cohort } \\
\text { study }\end{array}$ & $11 \mathrm{yr}$ & $\begin{array}{l}2191 \text { pharmacotherapy- } \\
\text { naive patients at } \\
\text { St. Michael's Hospital as } \\
\text { part of OECP }\end{array}$ & $\begin{array}{l}\text { Rates of investigation and } \\
\text { treatment in coordinator- } \\
\text { based FLS }\end{array}$ & $\begin{array}{l}\text { - Bone mineral density testing: } 84 \% \text { of } \\
\text { inpatients, } 85 \% \text { of outpatients } \\
\text { - Specialist or primary care assessment: } 85 \% \\
\text { of inpatients, } 79 \% \text { of outpatients } \\
\text { - Pharmacotherapy prescription: } 73 \% \text { of } \\
\text { inpatients, } 52 \% \text { of outpatients }\end{array}$ \\
\hline $\begin{array}{l}\text { Majumdar et } \\
\text { al., 2,15 2018, } 2019\end{array}$ & $\begin{array}{l}\text { Randomized } \\
\text { comparative } \\
\text { effectiveness trial } \\
\text { (C-STOP Trial) }\end{array}$ & $6 \mathrm{mo}$ & $\begin{array}{l}361 \text { pharmacotherapy- } \\
\text { naive patients aged } \\
\geq 50 \text { yr with upper } \\
\text { extremity FF in } \\
\text { Edmonton Health Zone }\end{array}$ & $\begin{array}{l}\text { Initiation of } \\
\text { pharmacotherapy with } \\
\text { low-intensity FLS (active } \\
\text { control) compared to } \\
\text { high-intensity FLS (nurse } \\
\text { case manager) }\end{array}$ & $\begin{array}{l}\text { - Initiation of pharmacotherapy: } 28 \% \text { in active } \\
\text { control group v. } 48 \% \text { in case manager group } \\
(p<0.001) \\
\text { - Appropriate care: } 44 \% \text { in active control } \\
\text { group v. } 76 \% \text { in case manager group } \\
(p<0.001) \\
\text { - Direct cost: } \$ 18 \text { for active control v. } \$ 66 \text { for } \\
\text { case manager } \\
\text { - Compared to usual care, case manager } \\
\text { intervention saved } \$ 564000 \text { and incurred } \\
18 \text { fewer fractures } / 1000\end{array}$ \\
\hline $\begin{array}{l}\text { Senay et al., }{ }^{12} \\
2019\end{array}$ & $\begin{array}{l}\text { Prospective cohort } \\
\text { study }\end{array}$ & $2 \mathrm{yr}$ & $\begin{array}{l}332 \text { patients aged } \\
>40 \text { yr with recent } F F \\
\text { and drug coverage }\end{array}$ & $\begin{array}{l}\text { Rates of prescription and } \\
\text { compliance, predictors of } \\
\text { noncompliance }\end{array}$ & $\begin{array}{l}\text { - } 89.5 \% \text { initiated pharmacotherapy } \\
\text { - Persistence rates: } 66.4 \% \text { at } 1 \mathrm{yr}, 55.6 \% \text { at } \\
2 \mathrm{yr} \\
\text { - Older and younger age, smoking, higher } \\
\text { bone mineral density, lower major FRAX risk } \\
\text { and missing follow-up visits were significant } \\
\text { predictors of noncompliance }\end{array}$ \\
\hline $\begin{array}{l}\text { Senay et al., }{ }^{13} \\
2020\end{array}$ & $\begin{array}{l}\text { Prospective cohort } \\
\text { study }\end{array}$ & $2 y r$ & $\begin{array}{l}532 \text { patients aged } \\
>40 \text { yr with recent FF }\end{array}$ & $\begin{array}{l}\text { Performance measures and } \\
\text { clinical outcomes after } \\
\text { implementation of FLS }\end{array}$ & $\begin{array}{l}\text { - } 88.7 \% \text { had bone mineral density testing } \\
\text { - } 86.6 \% \text { initiated pharmacotherapy } \\
\text { - Fracture incidence } 2.6 / 100 \text { person-years } \\
\text { - Decrease in type } 1 \text { collagen C-telopeptide } \\
\text { level of }>35 \% \\
\text { - Improved functional capacity (by } 14.4 \%- \\
63.7 \% \text { ), decreased pain level (by } 19.3 \%- \\
35.7 \% \text { ) } \\
\text { - No clinically important difference in quality } \\
\text { of life }(3.0 \%-15.2 \% \text { ) }\end{array}$ \\
\hline
\end{tabular}


patients with upper extremity FFs. Twenty-eight percent of the active control patients started bisphosphonate therapy, compared to $48 \%$ of those in the case manager group. These results echoed those of a previous study in which low-intensity interventions showed some benefit but left more than $70 \%$ of patients with nonhip FFs untreated. ${ }^{10}$

Investigators with the Osteoporosis Exemplary Care Program at St. Michael's Hospital, Toronto, found that the inclusion of a coordinator with a multidisciplinary team led to a reduction in the absolute number of hip fractures from 34 to 31 in the first year, leading to $\$ 48950$ in cost savings. ${ }^{14}$ They also determined that a case load of 350 500 patients would render it cost-effective to have a coordinator. Majumdar and colleagues, ${ }^{15}$ in Edmonton, came to similar conclusions: they determined that, for every 100 patients with whom the case manager worked after a nonhip FF (at a cost of $\$ 56$ per patient), 6 fractures would be prevented, leading to a net gain of 4 quality-adjusted life years and \$260000 in savings. The initial investment costs of the program were recuperated within 2 years. The C-STOP trial also provided similar support in terms of improved outcomes and cost savings for the implementation of type A models and, over time, type B models. ${ }^{2}$

To our knowledge, there have been no studies looking specifically at the effect of multidisciplinary teams on the care of patients with hip fractures, likely because patients with hip fractures are often managed as inpatients, whereas most multidisciplinary teams look at treatment outcomes in the outpatient setting. Although type B interventions have proven to be less effective than type A interventions such as multidisciplinary teams, the results are still promising ${ }^{19}$ and can be expected to be augmented by a more robust system of treatment. For example, the Bone Mineral Density Fast Track program identifies patients older than 50 years with FFs as part of the Ontario Fracture Clinic Screening Program. The fast track program led to the prevention of 7 hip fractures per 1000 patients screened and a gain of 20 quality-adjusted life years per $1000 .{ }^{19}$ A program in Manitoba that uses a clinical registry to calculate a Fracture Risk Assessment (FRAX) tool score takes a pseudomultidisciplinary team approach to reduce fractures. Leslie and colleagues ${ }^{23}$ validated the program's utility, both with and without bone mineral density testing, in predicting major osteoporotic fracture, particularly hip fracture. They concluded that the program can be used for primary prevention, helping with early identification of patients at high risk, and further follow-up in terms of treatment.

As multidisciplinary teams are often managed by nurses, it is important to validate the effectiveness of nurseinitiated treatment algorithms compared to physician decision-making alone. Senay and colleagues ${ }^{24}$ compared clinical decisions made by nurses using an order set and algorithm for the management of osteoporotic fractures in the Lucky Bone program, and those of a rheumatologist and an internist. Nurses succeeded in identifying all patients at risk, and $73 \%$ of patients were managed autonomously by nurses. The same treatment decision was made by the nurses and physicians in $96 \%$ of cases.

\section{Patient Perspectives on treatment}

Despite the advances that have been made through the integration of multidisciplinary teams in the transition of care in the context of FFs, there is still room for improvement in terms of patient and provider education. Adherence to bisphosphonate therapy can be as low as $50 \%$ within 12 months. ${ }^{25}$ We reviewed qualitative studies that used thematic analyses to determine barriers to starting or adhering to bisphosphonate treatment. Negative predictors of adherence to osteoporosis therapy were male sex, age younger than 65 years, nonmajor $\mathrm{FF}$, smoking, higher bone mineral density, lower FRAX tool risk and missed follow-up visits. ${ }^{1,12}$ The only predictor of compliance was being White. ${ }^{25}$ Luc and colleagues ${ }^{26}$ highlighted 3 key stages that influenced patient adherence: awareness, appraisal and action. Awareness was influenced mainly by the primary care provider, and his or her attitudes and ability to educate the patient about the role of bone mineral density testing. Appraisal of this information - essentially, converting the knowledge gained from the primary care provider into a decision - was influenced by the coordinator, as well as costs of medications for patients younger than age 65 . The final step, action, was largely influenced by the first 2 steps.

Swart and colleagues ${ }^{27}$ examined factors related to intentional noninitiation of bisphosphonate treatment in patients with a high risk for fracture in the primary care setting. Although primary care is not the focus of multidisciplinary teams, the study highlighted some transferrable themes underlying nonadherence to treatment, including insufficient medical advice, aversion to adverse effects, and awareness of osteoporosis and its severity. These factors can be addressed with superior patient education, and this should be kept in mind when an intervention is initiated after an FF, in order to improve both treatment initiation and adherence.

\section{How does Canada compare globally?}

The role of orthogeriatrician has been adopted in the UK and Australia. These physicians respond to the unique needs of older adults with fractures. They work on the wards, in the perioperative period, to optimize the function of this at-risk population; care should include appropriate osteoporotic management. ${ }^{28}$ In addition, by working closely with orthopedic surgeons, orthogeriatricians assist in creating a bridge in the transition from acute to chronic care of FFs. They can also help with patient education. ${ }^{29}$ 
Whereas primary care providers handle a wide variety of problems, orthogeriatricians focus almost exclusively on the management of osteoporotic fractures and the coordination of care surrounding these fractures. ${ }^{28}$ This should lead to the delivery of consistent messaging as well as increased patient adherence going forward. The role of the orthogeriatrician is closely integrated with that of the FLS. Through a dedicated ward, the orthogeriatric model leads to short time to surgery, and lower inpatient and 1-year mortality. ${ }^{30}$

These advanced FF and hip fracture care services have been pioneered through combined lobbying efforts of the British Geriatrics Society and the British Orthopaedic Association to create the National Institute for Health and Care Excellence (NICE) guideline "Osteoporosis: assessing the risk of fragility fracture" (Table 2), bestpractice tariffs and continuous real-time audit. ${ }^{31}$ The best-practice tariff provides reimbursement for hip fracture care that involves an assessment to initiate secondary prevention of osteoporosis. ${ }^{32}$ This community of support for the FLS model led to its implementation in nearly $40 \%$ of health care localities in England, Wales and Northern Ireland, and $66 \%$ of health care localities in Scotland. ${ }^{32}$ In contrast, the 2018 Osteoporosis Canada audit showed that FLSs had been adopted in only 3.0\% of Canadian hospitals. ${ }^{33}$ The institution of a national Canadian audit followed the model of the National Hip Fracture Database in the UK. Despite the current funding challenges in the Canadian health care system, the NICE guideline provides an important benchmark to encourage interprofessional collaborations to improve patient care.
The orthogeriatrician model is still in its infancy in Canada, but the widespread coordination of orthogeriatric services with FLSs should increase uptake. To some extent, the orthogeriatrician model has been coordinated through the Lucky Bone program, which schedules appropriate internal medicine referrals, ${ }^{24}$ and the Osteoporosis Exemplary Care Program at St. Michael's Hospital, with a close link to the Osteoporosis and Metabolic Bone Disease Clinic. $^{34}$

\section{FUTURE DIRECTIONS}

As the model of the multidisciplinary team suggests, the 3 aspects of managing patients with FFs are identification, investigation and treatment. ${ }^{33}$ At present, identification focuses on an initial FF, with subsequent initiation of treatment.

Vertebral fractures have a potentially important role in early identification of patients who would be candidates for treatment. When vertebral fractures are detected, often by the patient's primary care physician, they are usually treated effectively. ${ }^{35}$ However, vertebral fractures often go undiagnosed, owing to radiologic challenges and the varied clinical presentation. ${ }^{18}$ Distal radius fracture, another major osteoporotic fracture, is the most common upper extremity fracture and the most common fracture among adults older than 40 years. ${ }^{17}$ Distal radius fractures have an extremely important role in prediction of subsequent hip fracture: Chen and colleagues ${ }^{36}$ reported a hazard ratio of hip fracture in relation to distal radial fracture of 3.45 (95\% confidence interval 2.59-4.61). These important "bone attacks" should trigger appropriate investigations and interventions.

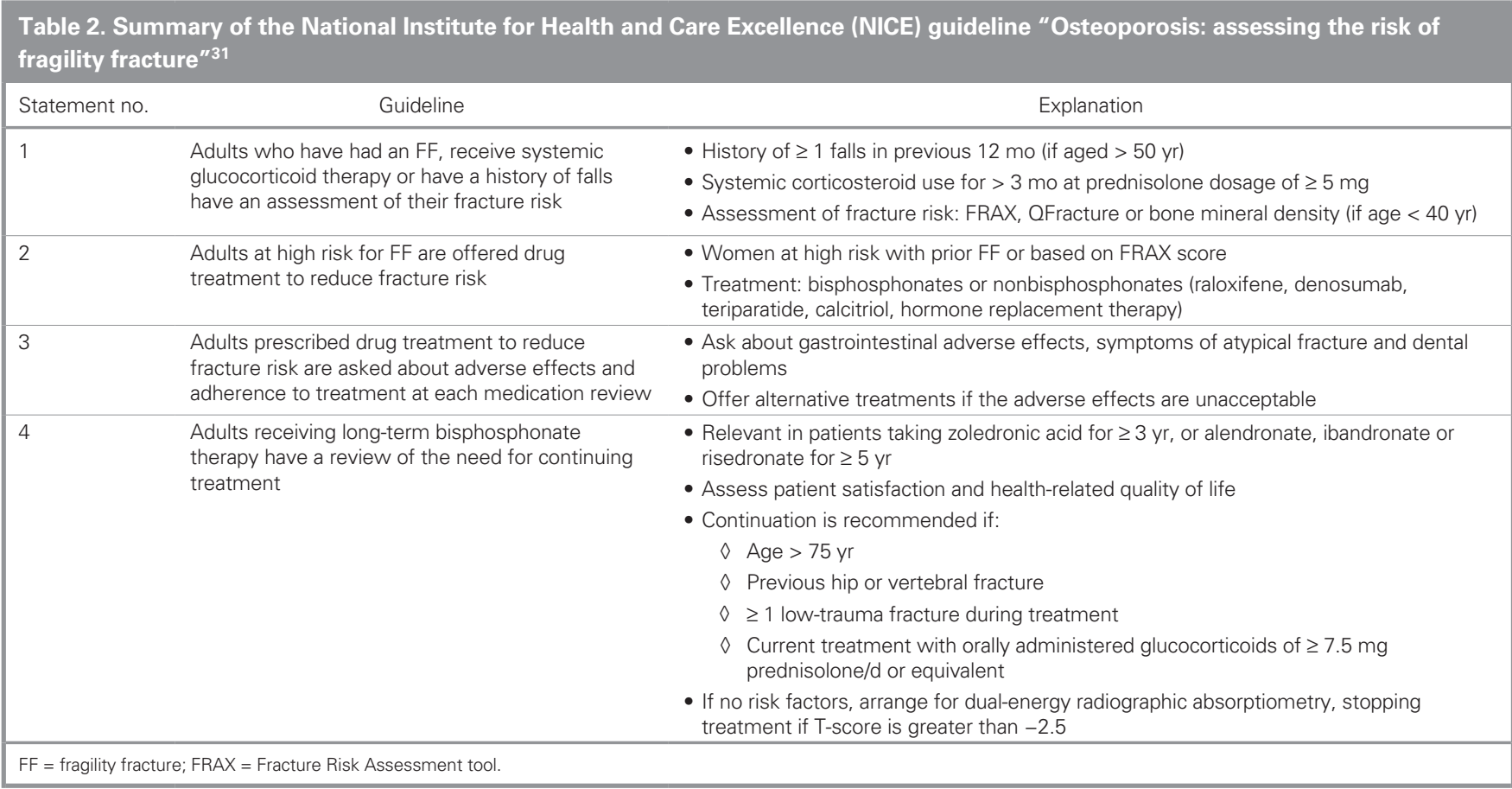


With better vertebral fracture detection and response to an initial FF, hip fractures can be prevented, with a cost savings of about $\$ 27000$ per fracture in direct costs in hospital and in the year after surgery. ${ }^{37}$ In addition, the assessment and treatment arms of care can be addressed through the role of nurse-led clinics, supervised by an orthogeriatrician, as done in Australia and the UK. By having a dedicated health care practitioner, specialized care tailored to patients with FFs can be delivered.

Despite the clear benefits of secondary fracture prevention programs, there exists a lag in their adoption. Of the hundreds of hospitals providing orthopedic care in Canada, only 45 (30 in Ontario) have a registered FLS. ${ }^{33}$ Economic factors are an issue in implementation of FLSs. Despite economic modelling showing not only feasibility, but also cost savings in centres that see as few as $350 \mathrm{FFs}$ per year, research has been conducted almost entirely at urban academic centres. ${ }^{14}$ Although the clinical effectiveness of FLSs at community centres has been confirmed, economic feasibility has not. ${ }^{9,11}$ In addition, investigation is usually funded by grants representing efficacy rather than effectiveness. To our knowledge, no information exists on the economic feasibility of FLSs designed to run indefinitely. In a mixed-methods study, Luc and colleagues ${ }^{38}$ showed that the context of implementation of FLSs can affect effectiveness, and location within a hospital - the same location as diagnosis - can reduce transitions within care and improve accessibility.

Other barriers to implementation include the lack of involvement of allied health care practitioners, as most FLSs exist as a partnership between a case manager and the treating physician. For example, pharmacists would be able to trigger follow-up for patients who have no refilled prescription. $^{38}$

Further investigation into the economic feasibility of situating FLSs in community centres, widespread integration of allied health care professionals and location of FLSs should lead to more widespread adoption of the FLS.

As with any new model of care, a system of evaluation should be in place to ensure that the goals of the program and the population are met. Gaboury and colleagues ${ }^{3}$ published a study protocol designed to evaluate programs to prevent secondary fractures. Although the patient recruitment measures and study populations will change, the data-collection parameters remain relevant (Box 2). These parameters provide a framework to ensure adequate assessment of multidisciplinary teams on multiple domains. Given that cost can be a barrier to program implementation and assessment, we indicate in Box 2 elements that we consider to be essential. This will provide a framework to ensure adequate funding of programs and monitor their effectiveness in treatment of FFs from a multidisciplinary perspective.
Box 2: Data collection parameters for evaluating protocol for programs to prevent secondary fracture ${ }^{3}$

- Treatment initiation and compliance: telephone surveys, validation with pharmacist*

- Time to first fall: diary of falls, telephone interview follow-up

- Fall-related hospital admissions: diary of falls, validation with hospital record

- FF-related deaths: hospital administrative database*

- Patient quality of life: EQ-5D-3L questionnaire*

- Patient physical activity: CHAMPS (Community Healthy Activities Mode Program for Seniors) tool

- FF-related costs: assessment, drugs, complication management, lost days of work, lost income, travel to hospital/rehabilitation, other out-ofpocket expenses*

- Admissions to long-term care: telephone survey

- Perceptions of care integration: exit questionnaire

- Satisfaction with FF program: refer to Berendsen and colleagues ${ }^{39}$

- Participant's expectations of program: Gignac Program Expectation Scale ${ }^{40}$

- Reasons for leaving the program: telephone interview*

$\mathrm{FF}=$ fragility fracture.

*Essential element for evaluating protocol.

\section{ConcLusion}

Hip fractures are a growing burden for the health care system and the individual patient. Multidisciplinary teams have proven to be effective at preventing $\mathrm{FF}$, which is often the initial warning event before a hip fracture. This is accomplished by improving treatment adherence in a costeffective manner. However, there is still room for improvement, in both the identification of patients at risk for hip fracture and patient adherence to therapy.

Affiliations: From the Faculty of Medicine, University of Toronto, Toronto, Ont. (Sanders); the Division of Orthopaedic Surgery, The Ottawa Hospital, Ottawa, Ont. (Dobransky, Liew, Papp, Harris, Grammatopoulos); and the Faculty of Health Sciences, University of Ottawa, Ottawa, Ont. (Cheaitani).

Competing interests: None declared.

Contributors: E. Sanders, J. Dobransky, S. Papp, A. Liew and G. Grammatopoulos designed the study. E. Sanders, L. Cheaitani, S. Papp and G. Grammatopoulos acquired the data, which E. Sanders, L. Cheaitani, N. Harris, S. Papp, A. Liew and G. Grammatopoulos analyzed. All authors wrote the manuscript, which J. Dobransky, L. Cheaitani, S. Papp and G. Grammatopoulos critically revised. All authors gave final approval of the article to be published.

Content licence: This is an Open Access article distributed in accordance with the terms of the Creative Commons Attribution (CC BYNC-ND 4.0) licence, which permits use, distribution and reproduction in any medium, provided that the original publication is properly cited, the use is noncommercial (i.e., research or educational use), and no modifications or adaptations are made. See: https://creativecommons. org/licenses/by-nc-nd/4.0/.

Funding: No funding was received for this study.

\section{References}

1. Roux S, Beaulieu M, Beaulieu MC, et al. Priming primary care physicians to treat osteoporosis after a fragility fracture: an integrated multidisciplinary approach. 7 Rheumatol 2013;40:703-11. 
2. Majumdar SR, McAlister FA, Johnson JA, et al. Comparing Strategies Targeting Osteoporosis to Prevent Fractures After an Upper Extremity Fracture (C-STOP Trial): a randomized controlled trial. 7 Bone Miner Res 2018;33:2114-21.

3. Gaboury I, Corriveau H, Boire G, et al. Partnership for fragility bone fracture care provision and prevention program (P4Bones): study protocol for a secondary fracture prevention pragmatic controlled trial. Implement Sci 2013;8:10.

4. Noordin S, Allana S, Masri BA. Establishing a hospital based fracture liaison service to prevent secondary insufficiency fractures. Int 7 Surg 2018;54:328-32.

5. Osteoporosis Canada. Toward a fracture free future: postoperative management of fragility fractures - a focus on osteoporosis care. COA Bulletin ACO Winter 2011. Available: www.osteoporosis.ca/ multimedia/pdf/COA_Bulletin_Winter_2012.pdf (accessed 2019 Aug. 21).

6. Fraser LA, Ioannidis G, Adachi JD, et al.; CaMos Research Group. Fragility fractures and the osteoporosis care gap in women: the Canadian Multicentre Osteoporosis Study. Osteoporos Int 2011;22: 789-96.

7. Kanis JA, Johnell O, De Laet C, et al. A meta-analysis of previous fracture and subsequent fracture risk. Bone 2004;35:375-82.

8. Bogoch ER, Elliot-Gibson V, Beaton D, et al. Fracture prevention in the orthopaedic environment: outcomes of a coordinator-based fracture liaison service. Foint Surg Am 2017;99:820-31.

9. Jaglal SB, Donescu OS, Bansod V, et al. Impact of a centralized osteoporosis coordinator on post-fracture osteoporosis management: a cluster randomized trial. Osteoporos Int 2012;23:87-95.

10. Majumdar SR, Beaupre LA, Harley CH, et al. Use of a case manager to improve osteoporosis treatment after hip fracture. Arch Intern Med 2007;167:2110-5.

11. Sale JEM, Beaton DE, Elliot-Gibson VIM, et al. A postfracture initiative to improve osteoporosis management in a community hospital in Ontario. F Bone Foint Surg Am 2010;92: 1973-80.

12. Senay A, Fernandes JC, Delisle J, et al. Persistence and compliance to osteoporosis therapy in a fracture liaison service: a prospective cohort study. Arch Osteoporos 2019;14:87.

13. Senay A, Perreault S, Delisle J, et al. Performance of a fracture liaison service in an orthopaedic setting: a report of key indicators and improvement of longitudinal outcomes. 7 Bone foint Surg Am 2020; 102:486-94.

14. Sander B, Beaton D, Bogoch E, et al. A coordinator program in postfracture osteoporosis management improves outcomes and saves costs. F Bone Foint Surg Am 2008;90:1197-205.

15. Majumdar SR, Lier DA, McAlister FA, et al. Cost-effectiveness of osteoporosis interventions to improve quality of care after upper extremity fracture: results from a randomized trial (C-STOP Trial). 7 Bone Miner Res 2019;34:1220-8.

16. Eisman JA, Bogoch ER, Dell R, et al.; ASBMR Task Force on Secondary Fracture Prevention. Making the first fracture the last fracture: ASBMR Task Force report on secondary fracture prevention. 7 Bone Miner Res 2012;27:2039-46.

17. Ostergaard PJ, Hall MJ, Rozental TD. Considerations in the treatment of osteoporotic distal radius fractures in elderly patients. Curr Rev Musculoskelet Med 2019;12:50-6.

18. Mitchell PJ. Best practices in secondary fracture prevention: fracture liaison services. Curr Osteoporos Rep 2013;11:52-60.

19. Yong JHE, Masucci L, Hoch JS, et al. Cost-effectiveness of a fracture liaison service - a real-world evaluation after 6 years of service provision. Osteoporos Int 2016;27:231-40.

20. Shakeri A, Adanty C. Romosozumab (sclerostin monoclonal antibody) for the treatment of osteoporosis in postmenopausal women: a review. 7 Popul Ther Clin Pharmacol 2020;27:e25-31.
21. Osteoporosis Canada. Appendix C: best practices for post-fracture osteoporosis care: fracture liaison services. Toronto: Osteoporosis Canada; 2013.

22. Osteoporosis Canada. Appendix D: other models of post-fracture osteoporosis care. Toronto: Osteoporosis Canada; 2013.

23. Leslie WD, Majumdar SR, Morin SN, et al. FRAX for fracture prediction shorter and longer than 10 years: the Manitoba BMD registry. Osteoporos Int 2017;28:2557-64.

24. Senay A, Delisle J, Raynauld JP, et al. Agreement between physicians' and nurses' clinical decisions for the management of the fracture liaison service (4iFLS): the Lucky Bone ${ }^{\mathrm{TM}}$ program. Osteoporos Int 2016;27:1569-76.

25. Ganda K, Schaffer A, Pearson S, et al. Compliance and persistence to oral bisphosphonate therapy following initiation within a secondary fracture prevention program: a randomised controlled trial of specialist vs. non-specialist management. Osteoporos Int 2014;25:1345-55.

26. Luc M, Corriveau H, Boire G, et al. Patient-related factors associated with adherence to recommendations made by a fracture liaison service: a mixed-method prospective study. Int 7 Environ Res Public Health 2018;15:944.

27. Swart KMA, Van Vilsteren M, Van Hout W, et al. Factors related to intentional non-initiation of bisphosphonate treatment in patients with a high fracture risk in primary care: a qualitative study. $B M C$ Fam Pract 2018;19:141.

28. Wilson H. Multi-disciplinary care of the patient with acute hip fracture: how to optimise the care for the elderly, traumatised patient at and around the time of the fracture to ensure the best short-term outcome as a foundation for the best long-term outcome. Best Pract Res Clin Rheumatol 2013;27:717-30.

29. Neuburger J, Currie C, Wakeman R, et al. Increased orthogeriatrician involvement in hip fracture care and its impact on mortality in England. Age Ageing 2017;46:187-93.

30. Dreinhöfer KE, Mitchell P, Bégué T, et al. A global call to action to improve the care of people with fragility fractures. Injury 2018;49: 1393-7.

31. Osteoporosis: assessing the risk of fragility fracture. Clinical guideline. London (UK): National Institute for Health and Care Excellence; 2012 (updated 2017 Feb. 7).

32. Mitchell P, Åkesson K. How to prevent the next fracture. Injury 2018;49:1424-9.

33. Report from Osteoporosis Canada's first national FLS audit: leading FLS improvement in Canada. Toronto: Osteoporosis Canada;2018.

34. Senay A, Perreault S, Delisle J, et al. Rationale, study design, and descriptive data of the Lucky Bone ${ }^{\mathrm{TM}}$ Fracture Liaison Service. Arch Osteoporos 2019;14:19.

35. Wong-Pack M, Naqvi N, Ioannidis G, et al. Evaluation of the fracture liaison service within the Canadian healthcare setting. 7 Osteoporos 2020;2020:6742604.

36. Chen CW, Le Huang T, Su LT, et al. Incidence of subsequent hip fractures is significantly increased within the first month after distal radius fracture in patients older than 60 years. 7 Trauma Acute Care Surg 2013;74:317-21.

37. Guy P, Sobolev B, Sheehan KJ, et al. The burden of second hip fractures: provincial surgical hospitalizations over 15 years. Can $\mathcal{F}$ Surg 2017;60:101-7.

38. Luc M, Corriveau H, Boire G, et al. Implementing a fracture followup liaison service: perspective of key stakeholders. Rheumatol Int 2020;40:607-14.

39. Berendsen AJ, de Jong GM, Schuling J, et al. Patient's need for choice and information across the interface between primary and secondary care: a survey. Patient Educ Couns 2010;79:100-5.

40. Gignac MA. An evaluation of a psychotherapeutic group intervention for persons having difficulty coping with musculoskeletal disorders. Soc Work Health Care 2000;32:57-75. 